\title{
O Direito Internacional repensado em tempos de ausências e emergências: a busca de uma tradução para o princípio da não-indiferença
}

\author{
International Law reconceptualized in a time of absences and \\ of emergency: the search for a translation to the Principle of \\ Non-Indifference
}

RICARDO ANTÔNIO DA SILVA SEITENFUS*

CRISTINE KOEHLER ZANELLA**

PÂMELA MARCONATTO MARQUES***

Rev. Bras. Polít. Int. 50 (2): 7-24 [2007]

\section{Introdução}

Em meados de 2000, às portas do novo século, o renomado sociólogo português, Boaventura de Souza Santos, em sua obra Crítica da Razão Indolente: Contra o desperdício da experiência faz uma advertência mandatória aos cientistas sociais:

A experiência social em todo o mundo é muito mais ampla e variada do que o que a tradição científica ou filosófica ocidental conhece e considera importante; esta riqueza social está a ser desperdiçada. É deste desperdício que se nutrem as idéias que proclamam que não há alternativa, que a história chegou ao fim e outras semelhantes; para combater o desperdício da experiência, para tornar visíveis as iniciativas e os movimentos alternativos e para lhes dar credibilidade [...] é necessário abandonar o modelo de racionalidade que chamo "razão indolente" [...] e adotar o que designo como "razão cosmopolita", fundada sobre a sociologia das ausências, a sociologia das emergências e o trabalho de tradução. (grifou-se)

Nesta breve passagem estão contidas três idéias centrais à compreensão desta análise, que busca inspiração na Teoria proposta por Boaventura: a) o entendimento de que, fora dos grandes centros de poder - leia-se Estados Unidos

\footnotetext{
* Professor titular de Relações Internacionais e de Direito Internacional Público no departamento de Direito e no Programa de Pós Graduação em Integração Latino-Americana da Universidade Federal de Santa Maria - UFSM (independencia@viavale.com.br).

** Professora da Faculdade de Direito de Santa Maria - Fadisma e Mestre em Integração Latino-Americana pela Universidade Federal de Santa Maria - UFSM (criskz.sma@terra.com.br)

*** Mestranda em Integração Latino-Americana pela Universidade Federal de Santa Maria - UFSM (pmarconatto@ yahoo.com.br.)
} 
e Europa - estão sendo conduzidas experiências alternativas àquelas hegemônicas nos âmbitos político, jurídico, social, econômico e cultural (sociologia das emergências); b) Que estas experiências têm sido vistas por estes centros como marginais, irrelevantes e/ou equivocadas, e, dentro desta lógica, são cinicamente produzidas como não existentes (sociologia das ausências); c) Que, no entanto, estas experiências se apresentam com um incrível potencial de sucesso e que, estando localizadas em grande parte no Hemisfério Sul, poderão servir de modelo entre estes países, com a necessária adaptação à realidade de cada um (trabalho de Tradução).

A análise que por hora se pretende fazer parte do pressuposto de que também no âmbito das complexas relações entre os Estados, experiências valiosas estão sendo desperdiçadas, ou porque encontram a sólida barreira da língua ou então porque partem de contextos os quais não se acredita como produtores de alternativas viáveis. É neste contexto que se busca situar o Princípio da NãoIndiferença. Elaborado em solo africano, com base no conhecimento popular que advertia não ser possível resignar-se diante do sofrimento alheio, esta nova doutrina pode ser compreendida, dentro da sociologia das ausências e emergências, como alternativa ao Princípio que, até então, havia figurado como cláusula pétrea nas Relações Internacionais: a Não-Intervenção. Apesar de não haver sido mencionado acima da linha do Equador, onde ainda é inexistente, as necessidades que levaram à adoção deste novo paradigma também são sentidas para além mar, chegando ao Brasil e à América Latina no momento em que se percebe que o desenvolvimento "ilhado" já não é mais possível.

O presente estudo se detém na busca do terceiro elemento proposto por Boaventura: o trabalho de tradução. Tradução no sentido de interpretação entre a experiência brasileira e a africana no que diz respeito ao Princípio da Não-Indiferença, confrontando as preocupações que lhe dão origem, o modo como é adotado e as diferentes respostas que com ele se pretende dar nestes dois contextos.

Tendo em vista o ineditismo do tema e a quase inexistência de teorização acerca do mesmo, o presente estudo assume o caráter de ensaio e experimentalidade que lhe condena à resignação diante da crítica e à constante reelaboração.

\section{Pelo não desperdício da experiência: Considerações acerca da utilização africana do Princípio da Não-Indiferença}

Falar do processo que leva à adoção do Princípio da Não-Indiferença em solo africano é falar, antes de tudo, de uma mudança de paradigmas sem igual na cultura securitária deste continente. Mais do que isso, é revisitar e trazer à tona a sabedoria destes povos, o espírito pan-africano que os entrelaça e ver a África como produtora de experiências alternativas a um modelo hegemônico, no qual sempre será vista com preconceito, descrédito ou, no máximo, com piedade. 
Dois acontecimentos nos parecem essenciais no traço desta análise ${ }^{1}$, uma vez que figuram como momentos em que, tomadas por uma forte noção de si, as nações africanas rejeitam a ordem vigente e passam a reivindicar uma ordem alternativa de concepção do e atuação no mundo. Estes momentos são: a) a descolonização massiva Pós-Segunda Guerra Mundial e b) o massacre de Ruanda em meados dos anos noventa. No bojo destes dois acontecimentos se dá a criação, respectivamente, da Organização da Unidade Africana e sua substituta, a União Africana. Ao estudo do confronto entre as urgências de cada um destes períodos e a cultura securitária adotada em cada um deles é que se destinará esta primeira seção da análise.

\section{A importância do Princípio da Não-Intervenção no contexto pós-colonial}

O contexto pós-Segunda Guerra Mundial, em que se dá a proliferação de organizaçōes internacionais defensoras dos Direitos Humanos e a incorporação da busca pela paz e defesa da autodeterminação das nações como tema de Fóruns Internacionais, oferece um cenário bastante profícuo ao movimento massivo dos países africanos rumo à independência. Sua posterior incorporação às Nações Unidas desenha, por conseguinte, um cenário bastante inusitado no âmbito desta organização: a prevalência de países "subdesenvolvidos" em seu quadro formador (Figura 1). Desta confluência resultou um substancial redirecionamento da agenda da ONU, até então voltada aos interesses daqueles que se vinham consolidando como novos pólos de poder mundial: Estados Unidos e URSS.

Figura 1

Membros das Nações Unidas por região geográfica, 1945-1988.

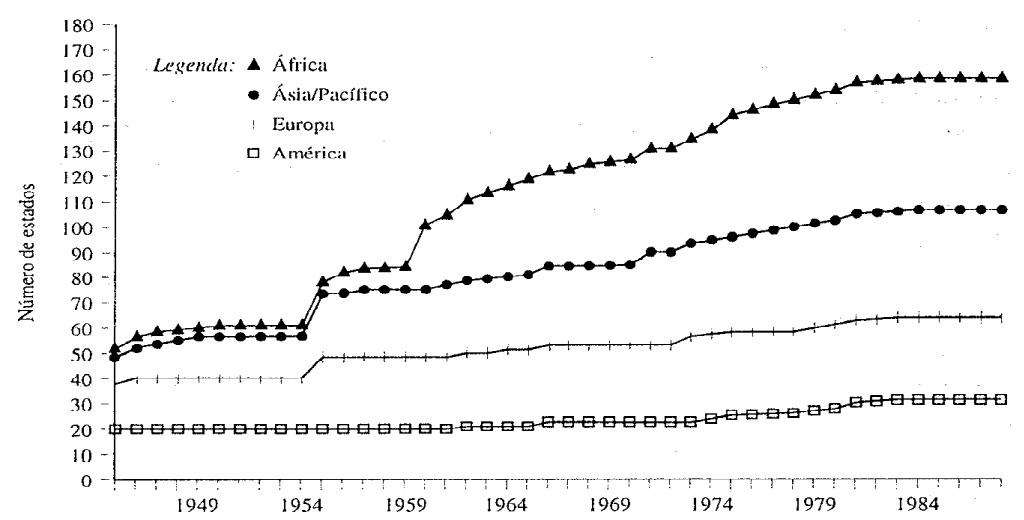

Fonte: TILLY apud RIBEIRO (2007)

1 A escolha destes dois momentos se deve, sobretudo, ao fato de ambos terem atuado como estopim de um incêndio que já se vinha armando há tempos. Assim, não devem ser entendidos como seu único fato gerador. 
A Conferência de Bandung, expoente desta nova arquitetura, realizada em 18 de Abril de 1955, contou com a participação de 29 Estados e 36 convidados, que representavam aproximadamente $60 \%$ da população mundial. Realizada ao alvedrio das potências americana e soviética, a Conferência sinalizou o interesse de seus membros em participar de forma ativa e propositiva no sistema internacional, recusando o alinhamento prévio aos blocos existentes, ao mesmo tempo em que conferiu apoio aos territórios afro-asiáticos em processo de descolonização.

Neste contexto, reagindo à forte ingerência externa que tentava imiscuir-se no vazio deixado pela descolonização, é aprovada, por Resolução da XV Assembléia Geral da ONU, a Declaração de Garantia de Independência dos Países Coloniais, a qual tinha por pilares: a) a defesa da autodeterminação dos povos; b) o repúdio a quaisquer tipos de ação armada e medidas de repressão dirigidas contra os povos dependentes; c) a defesa da integridade territorial destes países; d) a defesa da nãoingerência nos assuntos internos dos Estados e do respeito aos direitos soberanos de todos os povos; e) o entendimento de que a falta de preparação no domínio político, econômico, social ou no campo da educação não deveriam servir de pretexto para o retardamento da independência.

Em um cenário onde as necessidades estavam centradas na abolição de um sistema colonial residual e no impedimento de ingerências futuras partindo das novas potências, os Princípios defendidos nesta oportunidade pareciam os mais hábeis a garantir a emancipação em todas as suas formas. Tanto era assim, que nestes mesmos moldes foi aprovada, em 25 de Maio de 1963, na Etiópia, em um clima de euforia onde estavam presentes discursos acerca da Identidade Africana e do Pan-Africanismo², a Organização da Unidade Africana - OUA, cujo intuito maior estava centrado na construção de uma Nova África, capaz de atuar de maneira mais coesa e incisiva do cenário internacional. A OUA erigiu-se sobre os Princípios basilares do Direito Internacional: a igualdade soberana das Nações; a não ingerência nos assuntos internos dos Estados; e a livre-determinação dos povos.

No entanto, o cenário favorável no qual foi concebida não se estenderia por muito tempo ${ }^{3}$. Em breve, tanto a arquitetura internacional do pós-guerra se dissolveria com a queda do Muro de Berlim, quanto à geografia interna africana, herdada do período colonial e jamais revista, seria contestada por uma série de movimentos revoltosos. Assim, enquanto os Estados Unidos ampliavam

2 O Pan-Africanismo se refere à idéia de que todos os africanos possuem um em relação ao outro, uma afinidade espiritual e que, tendo sofrido juntos no passado, agora devem marchar juntos rumo a um futuro distinto e melhor. (EMERSON, 1962)

3 Duas importantes contestaçôes à ordem vigente foram levadas a cabo no período compreendido entre 60 a 80 : a primeira delas durante a Conferência das Nações Unidas para o Comércio e Desenvolvimento (C.N.U.C.E.D.), em 1964, onde foram lançadas as bases para aquele que ficaria conhecido como um Direito Internacional do Desenvolvimento, capaz de reduzir as assimetrias entre países desenvolvidos e aqueles em desenvolvimento. A segunda, em Maio de 1974, quando, por meio das resoluçôes 3.201 e 3.202 (S-VI) se adotou uma declaração e um programa de ação relativa à instauração de uma Nova Ordem Econômica Internacional (SEITENFUS, 2005). 
sua atuação hegemônica, a África ardia em conflitos étnico-religiosos internos aos Estados, que a pintavam como um típico quadro hobbesiano de tensão permanente, onde a violação dos direitos humanos passou a ser uma constante.

Neste cenário, uma cultura securitária fundada no Princípio da Não-Intervenção já não se mostrava suficiente para atender aos imperativos do novo tempo.

\section{O massacre de Ruanda e a emergência de um novo Princípio na União Africana}

Em 1994, a História africana é marcada por um dos episódios mais paradigmáticos no que concerne à violação dos Direitos Humanos. Não apenas porque em Ruanda foram mortos entre 800.000 e 1.000 .000 pessoas entre Tutsis e Hutus moderados - o que equivaleria a $11 \%$ do total da população e $4 / 5$ dos tutsis que viviam no país - mas porque foram mortos diante da mais completa indiferença de seus vizinhos e/ou das Organizações Internacionais.

Durante o massacre, a cultura securitária que conforma a Organização da Unidade Africana, assim como a Carta das Nações Unidas, parece ter servido à inércia destes agentes uma vez que, ao serem chamados ao auxílio, alegavam o dever de não interferir nos assuntos internos do país em questão, soberano em suas decisões ${ }^{4}$. Aí se constata aquela que talvez seja a mais grave debilidade do Direito Internacional contemporâneo pensado e institucionalizado desde e para os países desenvolvidos, como prudentemente apresentam Cilliers e Sturman (2002):

The concept of State sovereignty, on which the international system and the OUA were founded, presumes that each state has the power, authority and competence to govern its territory. For many African States, however, sovereignty is a legal fiction that is not matched by governance and administrative capacity.

Esta consciência, associada à lembrança ainda bem presente de outras graves violações, conduz à certeza de que algo significativo deveria ser feito para evitar novos massacres. Assim é que os Chefes de Estado Africanos substituem, em 2002, a Organização da Unidade Africana pela União Africana. Esta substituição vai muito além da semântica - que em si já se liberta do racionalismo Ocidental contido na idéia de "organização" e busca uma nova forma de se referir a si. Ela contem um novo modelo de integração continental, respaldado por uma cultura securitária que, em suas peculiaridades, pode ser compreendida como uma exeperiência alternativa em uma cena Internacional cuja arquitetura e funcionamento seguem padrões hegemônicos.

4 Mais tarde, por ocasião do 2000 Millennium Report da Assembléia Geral da ONU, o então Secretário-Geral, Kofi Annan, mostrar-se-ía bastante insatisfeito com esta resposta, a denunciar a desumanidade do Direito Internacional tradicional: "If humanitarian intervention is, indeed, an unacceptable assault on sovereignty, how should we respond to Rwanda, to a Srebrenica - to gross and systematic violations of human rights that offend every precept of our common humanity?" 
A nova cultura securitária supera uma doutrina de não-intervenção, necessária nos anos 60 a 80 , quando se davam os processos de descolonização no continente, mas incapaz de atender às demandas da nova época. Essa nova doutrina tem sido chamada de não-indiferença e tem suas raízes no conhecimento popular africano que afirma não ser possível desviar os olhos enquanto a casa de um vizinho está em chamas.

Transposta para o Acto Constictutivo da UA, esta doutrina vai respaldar a intervenção em um Estado Africano em duas circunstâncias: a) mudanças inconstitucionais de governo ( $\operatorname{art} .4^{\circ}$, " $\mathrm{p}$ " da Carta da UA), essencialmente no que diz respeito aos frequentes Coups d'états levados a cabo em solo africano, diante dos quais se tinha, até então, o que Williams(2005) chama "indiferença oficial" dos Estados e da OUA; e b) Intervenção humanitária nas chamadas "grave circunstances", entre as quais figuram crimes de guerra, genocídios e crimes contra a humanidade(art. 40" "h" da Carta da UA).

Ainda de acordo com o Acto Constictutivo, a iniciativa da intervenção poderá partir: a) de decisão da Assembléia Geral da UA ou, b) da solicitação de um Estado Membro. Aprovada a intervenção, sua implementação e a supervisão caberão a um novo órgão criado no âmbito da UA, the Peace and Security Council, o qual deverá conduzir-se de acordo com as linhas gerais do Relatório elaborado pela International Commission on Intervention and State Sovereignty (ICISS), acerca da Reponsabilidade de Proteger ${ }^{5}$. Este Relatório, além de estabelecer critérios a serem observados durante a intervenção, aconselha que ela seja conduzida por países que não estejam diretamente envolvidos no conflito, isto é, que com ele não tenham nada a ganhar ou a perder. ${ }^{6}$

Institucionalizada, esta nova doutrina securitária traz em si uma importante reflexão: a de que a inviolabilidade dos limites dos Estados não deve ser defendida com maior intensidade do que a vida e dignidade de seus habitantes. Não se quer dizer aqui que o baluarte da soberania deva ser, agora, impiedosamente enterrado, mas que, sim, ele deve passar por uma profunda resignificação. Talvez esta resignificação esteja centrada, conforme sugere o relatório da ICISS, na substituição de uma idéia de Soberania como Controle, por uma idéia de Soberania como Responsabilidade. Isto implica em que a justificativa para a inviolabilidade de um Estado não se deve mais dar pela eficácia de uma imposição legalmente

5 Acerca do planejamento de uma intervenção militar para proteção dos Direitos Humanos, o Relatório dispõe: Any new approach to intervention on human protection grounds needs to meet at least four basic objectives: a) to establish clearer rules, procedures and criteria for determining whether, when and how to intervene; b) to establish the legitimacy of military intervention when necessary and after all other approaches have failed; c) to ensure that military intervention, when it occurs, is carried out only for the purposes proposed, is effective, and is undertaken with proper concern to minimize the human costs and institutional damage that will result; $d$ ) and to help eliminate, where possible, the causes of conflict while enhancing the prospects for durable and sustainable peace.

6 Um exemplo de envolvimento com o conflito é a situação em que o Estado que encabeça a intervenção é limítrofe aquele em que se dá a violação, valendo-se da primeira para estancar o montante de refugiados que buscam segurança em seu território. 
aceita - e jamais contestada - de Soberania. ${ }^{7} \mathrm{O}$ respeito a sua autoridade implica, agora, em fazer reconhecer seu compromentimento e efetiva atuação na proteção do bem estar de seus cidadãos.

Assim, pode-se dizer que o Princípio da Não-Indiferença em solo africano assume as feições elencadas abaixo:

\section{Figura 2}

\section{As feições do Princípio da Não-Indiferença em território Africano}

$\begin{array}{ll}\text { 1. ORIGENS } & \begin{array}{l}\text { Tem suas origens na revolta diante da indiferença da comunidade } \\ \text { africana e internacional reafirmada por ocasião do massacre de } \\ \text { Ruanda; }\end{array} \\ \begin{array}{ll}\text { 2. ÂMBITO DE CONCEPÇÃO } \\ \text { 3. ÂMBITO DE }\end{array} & \begin{array}{l}\text { Está concebido dentro de uma cultura securitária, servindo, } \\ \text { consequentemente, à legitimação de um novo modo de atuação }\end{array} \\ \text { INSTITUCIONALIZAÇÃO } & \begin{array}{l}\text { Está institucionalizado na Carta da União Africana, tendo, portanto, } \\ \text { como moldura de aplicação, o continente africano; }\end{array} \\ \text { 4. ÂMBITO DE ATUAÇÃO } & \begin{array}{l}\text { Atua no sentido de legitimar e habilitar a intervenção militar em } \\ \text { duas situações: mudanças inconstitucionais de governo e grave } \\ \text { violação aos Direitos Humanos; }\end{array} \\ \text { 5. OUTRAS INSPIRAÇÕES } & \begin{array}{l}\text { Está intimamente ligado à Responsabilidade de Proteger e segue, } \\ \text { em sua aplicação, as diretrizes por ela elencadas. Encontra, ainda, } \\ \text { inspiração na cultura Pan-africana e a percepção do continente } \\ \text { como grande comunidade de destino que ela encerra. }\end{array}\end{array}$

Fonte: Elaboração Própria

Traçadas as considerações acerca da utilização do Princípio da Não-Indiferença em âmbito africano, partir-se-á, agora, para a análise experimental daquela que parece ser sua tradução brasileira ${ }^{8}$.

\section{A tradução da experiência: O Princípio da Não-Indiferença reconduzindo a política internacional brasileira}

Assim como na História africana, talvez não tenha havido, na história latino-americana, um contexto de necessidades tão preementes que exigisse uma subversão de paradigmas incrustrados na nossa política externa como o

\footnotetext{
7 Boaventura de Souza Santos (2004) já advertia para este modo de imposição de uma concepção: " $A$ Razão insegura e seus fundamentos não se inserem no mundo pela via da argumentação e da retórica. Não dá razões de si e impõe-se pela eficácia de sua imposição. E essa eficácia manifesta-se pela dupla via do pensamento produtivo e do pensamento legislativo: em vez da razoabilidade dos argumentos e do consenso que eles tornam possivel, a produtividade e a coerção legitima".

8 O termo "tradução" deve ser aqui compreendido dentro da Hermenêutica Diatópica proposta por Boaventura, como "procedimento capaz de criar uma inteligibilidade mútua entre experiências possiveis e disponíveis sem destruir sua identidade” (BOAVENTURA DE SOUZA SANTOS, 2002).
} 
momento presente. A soberania e os Princípios de sua lógica estatal-nacionalista - responsáveis pela indiferença africana em relação a massacres que aconteciam fora das fronteiras nacionais - fez, também por aqui, dos vizinhos - e só deles - a responsabilidade por seus problemas.

Ultrapassando a perspectiva do desenvolvimento como horizonte a ser alcançado no âmbito de cada uma das unidades de uma sociedade internacional atomizada em Estados-nação, a dinâmica atual impõe o reconhecimento das interligaçōes entre o sucesso do progresso político, econômico e social internos àqueles obtidos para além das fronteiras nacionais. E, assim, os problemas que afetam a vida dos vizinhos são, à medida que convulsionam a estabilidade do grupo, problemas que importam a todos os países da região. Dentro dessa nova lógica de problemas compartilhados surgem, paralelamente, espaços alternativos às clássicas vias que reduziram o universo de atores, realidades e relaçôes a dicotomias que carregam, arraigadas em si, fortes hierarquias, como as idéias de Norte/Sul, Emoção/Razão, Cultura/Ciência, etc.

A diferente feição que assumiu a política externa brasileira a partir do governo Lula - assim como a Carta Africana de 2002 - parece bem se inserir nessa nova dinâmica que adentra espaços não explorados e cria novas vias e perspectivas de cooperação. Para identificá-la, inicialmente apresentam-se as novidades, em seu aspecto pragmático, da política externa brasileira do período e, em seguida, identificam-se esses novos elementos a partir, essencialmente, dos discursos oficiais do atual Presidente do Brasil e do seu Ministro de Relações Exteriores. Ao fim, questiona-se a respeito da importância da institucionalização de um Princípio que contemple a perspectiva norteadora dessas novas prática e retórica da atuação externa brasileira.

\section{As urgências contemporâneas inspirando uma prática Internacional renovada}

Desde o século XIX, o Princípio da Não-Intervenção tem acompanhado a atuação externa brasileira. Num primeiro momento, se o defendeu com vistas à manutenção de sua independência da antiga metrópole e, logo, com o redesenhar do mapa de forças internacional, a invocação de tal pilar da política externa teria seu sentido transmutado para expressar a salvaguarda contra a investida de potências estrangeiras. Isso porque, muito embora tivesse mais força que seus vizinhos, e pudesse, na prática, atuar de forma mais ativa em seus territórios, o Brasil sempre temeu a possibilidade de que, ao adotar tais práticas intervencionistas e proferir um discurso que as sustentasse, pudesse vir a ser alvo de intervenções semelhantes por parte das grandes potências. Assim, o Princípio da Não-Intervenção desenhou-se como um dos mais consagrados Princípios dentre aqueles que regem as relações internacionais da República Federariva do Brasil, tendo mesmo merecido um lugar na Carta Fundamental de 1988 (VIZENTINI, 2001). 
A partir do atual governo, tem-se visto uma atuação diferenciada de política externa. As necessidades econômicas, sociais e políticas pelas quais tem passado as populações de alguns países forçaram a estruturação de relaçôes internacionais imbuídas de valores humanistas que, como tais, escapam às lógicas reducionistas que pautaram as atuações dos Estados nacionais até então. Essa atuação internacional diferenciada não encontra sua razão de ser no persistente discurso do interesse nacional, mas edifica-se sobre um sentimento de responsabilidade global cuja feição universalizante se encontra no que em comum de humano cada indivíduo encerra. No indivíduo e na assecuração da sua dignidade enquanto ser humano, na possibilidade de melhoria de sua condição de vida, está a razão e o fim da atuação internacional de um Estado que conseguiu, à semelhança da experiência africana, superar aquela que Bauman (2006) denominou como "lógica do entrincheiramento local".

Três exemplos trazem elementos que revelam a inauguração desta nova política externa por parte do Brasil.

O primeiro consiste no perdão de dívidas estrangeiras. Desde o início de seu mandato, o presidente Lula perdoou as dívidas de Bolívia (US\$ 52 milhões), Cabo Verde (US \$ 2,7 milhōes), Gabão (US\$ 36 milhões), Moçambique (US\$ 331 milhões, equivalentes a 95\% da dívida deste país com o Brasil) e Nigéria (US\$ 84 milhôes), entre outros ${ }^{9}$. Em si, esses países sustentam em comum a condição de estarem entre as nações com os menores índices de desenvolvimento mundiais ${ }^{10}$.

O segundo refere-se ao caráter da participação brasileira para a estabilização, reconstrução e viabilização do Haiti.

A experiência brasileira no território do país caribenho iniciou-se em maio de 2004, no âmbito da Missão de Estabilização das Nações Unidas no Haiti (MINUSTAH). Essa não é a primeira vez que o Brasil participa de uma missão deste tipo, mas alguns fatores tornam essa atuação especial e paradigmática: a) o contingente brasileiro no Haiti é um dos maiores já deslocados sob o mandato da ONU; b) pela primeira vez a América do Sul tem a maioria da tropa em uma Missão de Paz da ONU; c) pela primeira vez o Brasil tem o comando de uma força de paz internacional; d) a proposta brasileira ultrapassa os objetivos de garantir a instauração de condições seguras para o desenvolvimento de um processo que garanta a livre expressão do povo haitiano para a escolha de seus dirigentes.

O Haiti é um dos países mais pobres do mundo. De acordo com estatísticas oficiais, $80 \%$ da população vive abaixo da linha da pobreza e pouco mais de $50 \%$ desta é analfabeta. Nas cidades, a maior parte da população passa fome e vive em favelas, onde o esgoto corre a céu aberto (SADER et al., 2007). Nessas condições, agravadas pelas violentas crises políticas que há décadas assolam o país, é inconteste

9 Diário do Senado, disponível em: http://www.senado.gov.br/sf/publicacoes/diarios/pdf/sf/2004/09/1 5092004/29479.pdf.

10 Conforme dados do IDH 2006. 
o risco iminente e irreparável de vida que correm milhares de seres humanos e que fazem urgente a cooperação internacional imediata. Mesmo ciente de suas próprias necessidades, o Brasil destacou esforços não só na seara militar mas também, mais amplamente, em outras dimensões, como a social, técnica e cívica, para assistir a população haitiana e para chamar a atenção da comunidade internacional para as necessidades do país. É nessa perspectiva ampliada de atuação que podem ser vistas ações como a cessão de itens da ração dos soldados à população, o envio de centenas de quilos de medicamentos pelo Ministério da Saúde brasileiro e o jogo de futebol Brasil-Haiti, promovido pela Confederação Brasileira de Futebol. Também evidenciando que sua ação se propõe a reestruturar de forma sustentável o espaço haitiano, o Brasil enviou uma ação multidisciplinar de cooperação técnica para identificar setores em que o país poderia colocar à disposição do Haiti conhecimentos e mão-de-obra especializada para a reconstrução da infraestrutura e instituições do país caribenho (SOUZA; ZACCARON, 2006). Tal iniciativa, apesar de não demandar enormes montantes de recursos financeiros, aporta auxílio a um país de tudo necessitado e significa uma linha importante de cooperação que se inaugura entre dois países que, apesar das escassas relaçóes que mantém hoje em dia, carregam nas populações que formaram suas sociedades laços étnicos, culturais, religiosos e históricos comuns.

Por fim, ressalta-se a postura do governo brasileiro que reconheceu a nacionalização dos hidrocarbonetos bolivianos, deflagrada em maio de 2006, como ato soberano legítimo do Estado andino. Em que pesem as fortes críticas que lhe endereçaram a mídia nacional, o presidente brasileiro demonstrou coerência ao reconhecer os direitos de propriedade sobre os recursos naturais, tanto pelo fato de refletir um direito reivindicado pelo próprio Brasil há muito tempo (lembrese da nacionalização brasileira marcada pela conhecida campanha "O Petróleo É Nosso", realizada em 1953), quanto pelo fato de corresponder a declarações internacionais firmadas pelo país, como, por exemplo, a Resolução 1803, da Assembléia Geral das Nações Unidas, que definiu para os Estados a "soberania permanente sobre suas riquezas e recursos naturais", além de dispor que estes podem livremente estabelecer as regras para a "exploração, o desenvolvimento e a disposição de tais recursos” (ZANELLA; MARQUES, 2006).

A postura do governo brasileiro no caso da nacionalização boliviana levou em consideração tanto a coerência com a normativa internacional pelo próprio Brasil votada, como as necessidades práticas de um país que, apesar de suas riquezas naturais, manteve, durante mais dois séculos, o status de mais pobre da América do Sul. A atitude brasileira partiu de uma perspectiva que considera responsabilidade de todos a busca de um desenvolvimento mais uniforme das nações, capaz de melhorar fortemente as condições de existência e os níveis econômicos das populações dos países menos desenvolvidos. Mais uma vez nota-se, aqui, que a revalorização dessa perspectiva ampliada de responsabilidade, partindo de um país marginal no sistema internacional para outro, também marginal, quebra com 
a idéia de que a ajuda e a cooperação podem somente se dar no âmbito e sentido das realaçôes Norte/Sul ou Desenvolvidos/Subdesenvolvidos ${ }^{11}$. Também aqui está presente uma nova perspectiva de atuação que não reproduz ante os mais fracos os esquemas de dominação que lhes são impostos a partir das potências mundiais. Eis, enfim, um terceiro exemplo de uma política que não fecha os olhos ante o sofrimento e as carências dos menos favorecidos e que, ao fazê-lo, instrumentaliza a política internacional brasileira de vias para estabelecer contatos, relações e dinâmicas de cooperação a partir de uma perspectiva ampliada que contempla, além dos canais mantidos com os países desenvolvidos, também aqueles que podem ser estabelecidos com os subdesenvolvidos.

Os três exemplos citados trazem elementos que permitem visualizar o caráter inovador da política externa do presidente Lula. São elementos que evidenciam a reorientação da atuação externa brasileira também considerando a solidariedade e responsabilidade devidas para com as populações que sofrem em função de conflitos internos, carências de todas as ordens, repressão, falência do Estado, impossibilidade ou ausência de vontade deste de reduzir tais sofrimentos. Tal como na África, a atuação do Brasil começa a ser orientada pela convicção de que já não é possível desviar o olhar quando a casa do vizinho arde em chamas. Nisso não há ineditismo. A sensação de que a minimização das desigualdades substanciais entre os países é uma condição sine qua non para o avanço geral também foi vivenciada nas décadas de 60 e 70, quando o contexto da descolonização ensejou uma série de propostas a partir de países subdesenvolvidos. Entre essas propostas estavam um Novo Direito e uma Nova Ordem Econômica Internacional. No entanto, enquanto nesse momento, o discurso não encontrou na prática um modo de viabilizar a realização de seus anseios, o presente inverte esta lógica e coloca a prática à frente da retórica. Nesse sentido é que os discursos, tanto o Ministro de Relaçōes Exteriores quanto do Presidente do Brasil devem ser compreendidos, como uma tentativa de fundamentar essa nova lógica de atuação internacional do país.

\section{O Princípio da Não-Indiferença perpassando o discurso político brasileiro}

Escorando a prática progressiva - porque acrescida de valores universais, que ultrapassam o "entrincheiramento do local" - e revolucionária - porque desafia as lógicas reducionistas a que os Estados viam presas as possibilidades de suas atuações externas - alguns agentes politicamente ativos da cena nacional vêm fazendo em seus discursos referências em relação à redefinição de prioridades e instrumentos da atuação internacional do país. Em especial neste caso, onde o discurso sucedeu ou acompanhou a prática, através da manifestação pública,

11 Também na África a superação da idéia de que a ajuda teria necessariamente partir do Norte desenvolvido resultou na ampliação e criação de novos canais de cooperação regionais, como foi o caso, inicialmente, da OUA e é, hoje, a UA. 
Celso Amorim e Lula buscaram oficializar as intenções que justificaram as feições de determinada política e tentaram estabelecer a concatenação, no plano das idéias, que dá sustentação ao que vem sendo executado.

O discurso do Presidente Lula é, desde seu início, marcado por uma forte perspectiva humanista, que reconhece a importância e busca sobrepor os valores da solidariedade e da cooperação àqueles da indiferença e omissão perante os excluídos $^{12}$. Essas intenções são desde logo anunciadas como parte de uma política que pretende vê-las em operação, superando as posturas meramente reativas que habitualmente acompanham os discursos do gênero. São suas palavras, em discurso por ocasião da formatura de uma nova turma de diplomatas brasileiros, em setembro de 2005:

Não aceitamos como fato consumado uma ordem internacional injusta (...). Nossa atuação diplomática é fundada na defesa de Princípios, mas também na busca de resultados. Tem uma dimensão utópica sem deixar de ser pragmática.

Mais adiante o presidente menciona o Princípio da Não-Indiferença como norteador dessa política internacional que seu governo propôs-se a seguir:

Em um mundo globalizado e interdependente, nossa contribuição à paz e à democracia é determinada pelo Princípio da Não-Indiferença. Por isso nos engajamos nos esforços de estabilização do Haiti. (Grifou-se)

Menciona, ainda, outros novos caminhos da atuação internacional de seu governo, como a crescente intensificação das relações com países africanos e o incremento do diálogo Sul-Sul. Ao fim, volta a enfatizar a importância desse Princípio que sensibiliza o país para o que acontece além-fronteira através de uma alegoria que faz referência à importância do desenvolvimento conjunto da América do Sul:

(...) porque não seremos ricos se tivermos nas nossas costas países miseráveis onde persiste a fome, o desemprego e a miséria.

Essas palavras anunciam que a política internacional brasileira atual está a serviço dos valores que o governo prioriza, dentre os quais estão aqueles ligados ao Princípio da Não-Indiferença que o Presidente, através da prática e do discurso, colabora para delinear.

As palavras do Ministro Celso Amorim revelam ainda mais claramente esse caráter da diplomacia do governo Lula. Em 2003 ela estava bem definida enquanto Princípios norteadores e propostas que demonstram a consciência do

12 Neste aspecto o discurso do Presidente Lula apresenta traços que o aproximam dos presidentes africanos, como, por exemplo, aquele de Alpha Oumar Konaré, ex-presidente de Mali e da Comissão da UA, quando, referindo-se ao dever de cooperação em relação ao episódio de Darfur, afirma: "somos a favor de que a África assuma o seu dever de não-indiferença (que se traduz em) uma ingerência solidária” (Ministério das Relações Exteriores). 
governo da necessidade de assumir responsabilidades na cena internacional para fazer frente aos desafios contemporâneos:

A ação diplomática do governo Lula está impregnada de uma perspectiva humanista, que faz com que seja, a um só tempo, instrumento de desenvolvimento nacional e defensora de valores universais (2003, p. 155).

A mesma aspiração por desenvolvimento e progresso social, que moldam a ação governamental em âmbito interno, nos mobilizará nos planos regional e global. Nossa aspiração por paz e solidariedade passa necessariamente por uma atenção detida para as carências dos menos favorecidos (2003, p. 160).

Dois anos mais tarde, em discurso pronunciado por ocasião da XXXV Assembléia Geral da Organização dos Estados Americanos (OEA), a perspectiva humanitária da atuação internacional brasileira volta a ser reforçada pelo Ministro. Nesta ocasião, porém, após confirmar que um dos apoios da diplomacia brasileira encontra-se no Princípio da Não-Intervenção em assuntos internos, ressalta que isso não deve servir de pretexto para negar a solidariedade ativa do país:

A diplomacia brasileira pauta-se pelo Princípio de Não-Ingerência em assuntos internos, consagrado em nossa Carta. O governo do Presidente Lula tem associado a esse Princípio básico uma atitude que descrevemos como de "não-indiferença". Temos prestado nosso apoio e solidariedade ativos em situaçōes de crise, sempre que somos solicitados e consideramos ter um papel positivo (AMORIM, 2005). (Grifou-se)

Cerca de um ano mais tarde o tom do discurso e a importância da atitude de Não-Indiferença seriam novamente invocados, na subsequente reunião Assembléia Geral da OEA:

É muito importante que todos nós sejamos capazes de praticar a não-indiferença, isto é, um engajamento no auxilio sempre que solicitado, para a consolidação democrática dos países. Mas, ao mesmo tempo, também é importante nos abstermos de interferir em processos internos. É isso que tem guiado a política do Presidente Lula, baseada na integração, baseada na amizade, baseada na não-indiferença, mas também na nãointevenção (AMORIM, 2006). (Grifou-se)

Em todas as falas é interessante notar que a menção à Não-Indiferença aparece sempre associada a uma atuação, a uma prática. Sua utilização se dá, portanto, já no contexto de algo que vem se operando e que, assim, já ultrapassou a fronteira do programático e atingiu o pragmático. Essa nuance é importante, pois na ocasião dos pronunciamentos já estavam em curso experiências práticas de solidariedade ativa, como as citadas na seção anterior.

Por fim, a Não-Indiferença como Princípio orientador de uma nova dinâmica de Política Externa veio citada por Ricardo Seitenfus, membro da Comissão Jurídica Interamericana da OEA, em seu pronunciamento por ocasião da Sessão Especial 
sobre os Princípios de Direito Internacional contidos na Carta da Organização dos Estados Americanos, realizada em Washington, em março de 2007.

Ressalta o professor que, apesar de ainda não estar consolidado como Princípio, o caráter das atuações internacionais de alguns países das Américas no Haiti tem possibilitado a vivência prática de valores que estão em sua base, como as idéias da responsabilidade solidária dos membros da Organização por um desenvolvimento integral. Em suas palavras:

Sem prejuízo da aplicação do Princípio da não-intervenção, é urgente e necessária a distinção entre este e um novo Princípio de direito internacional que se afirma progressivamente - trata-se do Princípio da Não-Indiferença. (...)

A operacionalização do Princípio da Não-Indiferença se faz a partir do conceito de diplomacia solidária. Agindo coletivamente, desprovidos de interesses menores e subalternos, um grande número de países das Américas fornece na atualidade o exemplo desta nova forma de perceber, além da fria razão de Estado, os desafios dos Homens. A atuação desses países no Haiti constitui esta nova perspectiva para as relações interamericanas (SEITENFUS, 2007).

Esta harmonia nos discursos sobre a diplomacia do governo Lula, que se encontram entre agentes politicamente ativos, confere uma legitimação simbólica às açôes que já estão em curso. Acontece aqui um ajustamento particular, em que as práticas de cooperação antecedem a sustentação em diferentes foros do discurso da solidariedade. Se se tiver em consideração, por exemplo, o que aconteceu durante as décadas de 60 e 70, em que apesar dos discursos e documentos internacionais firmados, pouco se conseguiu fazer de efetivo para melhorar as condições de vida das populações dos países subdesenvolvidos, percebe-se a diferença da dinâmica que vem se desenvolvendo em termos de Política Internacional sob o atual governo. Essa dinâmica é, sem dúvida, nova, e os valores que a inspiram compõem o arcabouço que dá sustentação àquele que vem se definindo como Princípio da Não-Indiferença.

\section{Figura 3}

As feições do Princípio da Não-Indiferença na Política Internacional Brasileira.

\begin{tabular}{|ll|}
\hline 1. ORIGENS & $\begin{array}{l}\text { Tem suas origens no caráter diferenciado impresso pela Política } \\
\text { Internacional do governo do Presidente Lula, e se coaduna com } \\
\text { suas iniciativas e discursos no âmbito internacional, relativas à } \\
\text { redução das desigualdades sociais; }\end{array}$ \\
\hline 2. ÂMBITO DE CONCEPÇÃO & $\begin{array}{l}\text { Está concebido dentro de uma cultura de solidariedade internacional } \\
\text { e responsabilidades compartilhadas; }\end{array}$ \\
\hline $\begin{array}{l}\text { 3. ÂMBITO DE } \\
\text { INSTITUCIONALIZAÇÃO }\end{array}$ & $\begin{array}{l}\text { Não está institucionalizado, aparecendo apenas nos discursos de } \\
\text { agentes politicamente ativos, como o Presidente da República e o } \\
\text { Ministro de Relações Exteriores do Brasil; }\end{array}$ \\
\hline
\end{tabular}


Atua de modo a orientar a atuação internacional do país. Até agora, se coaduna com a postura do governo frente aos perdões de dívida

4. ÂMBITO DE ATUAÇÃO concedidos a países pobres, o reconhecimento de nacionalizações em países nos quais empresas brasileiras têm forte participação econômica, o envio de tropas brasileiras ao Haiti, etc.

Está intimamente ligado a uma Teoria de co-responsabilidade, seguida por um forte apelo à solidariedade ativa dos países em desenvolvimento

5. OUTRAS INSPIRAÇÕES em relação àqueles menos desenvolvidos (Diplomacia Solidária). Inspira-se ainda na lógica do Direito Internacional do Desenvolvimento e de uma Nova Ordem Econômica Internacional, forjados nas décadas de 60 e 70, ambos calcados na busca de justiça social.

Fonte: Elaboração Própria

\section{Conclusão}

A História tem contribuído para que se desenhe, de tempos em tempos, às populações de países marginalizados, um cenário no qual é possível tomar noção das mazelas de sua existência e, assim, lançar-se em busca de voz e vez em um contexto que lhes é hostil.

Durante o breve século XX este cenário foi esboçado algumas vezes - nos anos 60 com a forte corrida pela independência nos continentes asiático e africano; nos anos 70 com a tentativa de lançar as bases de um Direito Internacional do Desenvolvimento, alicerçado sobre uma Nova Ordem Econômica Internacional - sem que, no entanto, emergisse dos rabiscos iniciais a grande obra final, capaz de subverter a lógica de dominação que condena alguns países a mais completa marginalidade.

Às portas do século XXI, esta oportunidade parece ser novamente oferecida. No entanto, para que se possa vê-la como tal, é necessário analisá-la com olhos despidos daquela concepção que rege a experiência ao alvedrio da vontade, manipulando nossa compreensão e consequente atuação no mundo, nas engrenagens de uma lógica que Boaventura chamou "indolente". Não basta, no entanto, que conheçamos as inúmeras experiências alternativas que têm sido levadas a cabo na vastidão deste planeta sem que elas possam ser consistentemente traduzidas à nossa realidade, fazendo sentido no lugar que ocupamos e em relação às urgências que enfrentamos.

Nesse sentido é que se pretendeu inserir o presente estudo, uma vez que traz à tona uma experiência que se dá em uma região marginalizada do cenário clássico das Relações Internacionais, e tem servido de inspiração para compreender os novos mares pelos quais tem navegado a política internacional brasileira. Não que as experiências sejam as mesmas, também porque elas respondem a urgências distintas, de maneiras distintas. Mas o traço em comum que as liga está na experimentação de fórmulas próprias e alternativas para problemas que já não encontram resposta em lógicas hegemônicas que, não raro, são a própria razão da existência das mazelas do mundo subdesenvolvido. 
$\mathrm{Na}$ África, a Não-Indiferença vem responder à insuficiência de uma cultura securitária baseada na Não-Intervenção para resolver dilemas que ultrapassam as fronteiras e capacidades do Estado. Já no Brasil, a Não-Indiferença vem legitimar uma atuação internacional que teve de ser refundada para melhor responder às demandas de um continente em crise, onde não se pode mais ignorar que não há desenvolvimento possível em meio à miséria e à desesperança.

De distinto entre as duas experiencias está o fato de que em territorio africano a Não-Indiferença é inicialmente incorporada ao discurso dos presidentes, para então ser institucionalizada no âmbito da Carta Africana e, assim, viabilizar a intervenção. Esta lógica é invertida pela experiência brasileira, onde o princípio vem conformar e legitimar uma prática que já vem sendo adotada. $\mathrm{O}$ passo seguinte seria a institucionalização do Princípio. No entanto, a transformação da práxis em Direito deve levar em conta aspectos que definam sua abrangência e seus limites, para que assim, consiga-se delimitar critérios de operacionalização da Não-Indiferença, de modo que ela possa constituir-se em efetivo agente da solidariedade, e não apenas em mais uma bela roupagem para a ingerência dos mais fortes sobre os mais fracos.

Este processo exige, no entanto, um longo caminho de amadurecimento e consolidação, como intuiu Ricardo Seitenfus (2007):

Este Princípio dialoga para além do Estado, pois se dirige à Humanidade. Por ser jovem, carece de uma teorização e de uma prática que o torne geral e constante, para que se transforme em Direito. Se por um lado o conceito e a juridicidade da não-intervenção estão consolidados, há um longo caminho a ser trilhado até se consolidar como conceito e se tornar realidade o Princípio da Não-Indiferença.

Recebido em 19 de agosto de 2007 Aprovado em 25 de novembro de 2007

\section{Bibliografia}

AMORIM, Celso. Palestra no Instituto Rio Branco "A diplomacia do governo Lula" em 10 de abril de 2003. Wilhelm Hofmeister (org.), Anuário Brasil-Europa. Rio de Janeiro: KonradAdenauer-Stiftung, 2004.

BARDIN, Laurence. Análise de Conteúdo. Lisboa, Portugal: Ed. 70 Ltda., 1977.

BAUMAN, Zigmunt. Europa: uma aventura inacabada. Rio de Janeiro: Ed. Jorge Zahar, 2006;

BOAVENTURA DE SOUSA SANTOS. Para uma sociologia das ausências e uma sociologia das emergências. Revista Crítica de Ciências Sociais, 63, Outubro 2002, pp 237-280;

BOURDIEU, Pierre. O Poder Simbólico. Rio de Janeiro: Ed. Bertrand Brasil, 1989;

BRASIL. Celso Amorim. Ministro de Estado das Relaçôes Exteriores. Discurso na abertura do debate geral da 60a Sessão da Assembléia Geral das Naçôes Unidas em Nova Iorque, 17 de 
set. de 2005. Disponível em: <http://www.mre.gov.br/portugues/politica_externa/discursos/ discurso_detalhe3.asp?ID_DISCURSO=2691. Acesso em: 3 jul. 2007>.

BRASIL. Celso Amorim. Ministro de Estado das Relações Exteriores. Discurso por ocasião da XXXVI Assembléia-Geral da OEA, em São Domingos, República Dominicana, 5 un. 2006. Disponível em: <http://www.mre.gov.br/portugues/politica_externa/discursos/discurso_ detalhe3.asp?ID_DISCURSO=2853. Acesso em: 3 jul. 2007>.

BRASIL. Luiz Inácio Lula da Silva. Presidente da República. Discurso na Reunião de Alto Nivel da Assembléia Geral das Naçôes Unidas (Metas do Milênio). Disponível em: <http://www.mre. gov.br/portugues/politica_externa/discursos>. Acesso em: 3 jul. 2007;

BRASIL. Luiz Inácio Lula da Silva. Presidente da República. Discurso na Cerimônia de Formatura da Turma "Celso Furtado" (2002) do Instituto Rio Branco. Disponível em: <http://www.mre.gov. br/portugues/politica_externa/discursos>. Acesso em: 3 jul. 2007;

BRASIL. Luiz Inácio Lula da Silva. Presidente da República. Discurso na abertura do Colóquio "Brasil: Ator Global" em Paris, França, 2005. Disponível em: <http://www.mre.gov.br/portugues/ politica_externa/discursos>. Acesso em: 3 jul. 2007;

BRIGAGÃO; Clóvis; CAMPOS MELLO, Valerie. Diplomacia Cidadã: Panorama Brasileiro de Prevenção de Conflitos Internacionais. Rio de Janeiro: Gramma: Fundação Konrad Adenauer, 2006;

CILLIERS; STURMAN. The right of intervention: Enforcement challenges for the African Union. African Security Review, Vol. 11, n. 3, 2002;

EMERSON, Rupert, Pan-Africanism. International Organization. vol.16, n.2, 1962;

INTERNATIONAL COMMISSION ON INTERVENTIONAND STATE SOVEREIGNTY. The Responsibility to Protect: Report of the International Commission on Intervention and State Sovereignty. December 2001. Publicado por International Development Research Centre, Canadá. Disponível em: < http://www.idrc.ca>;

$\mathrm{KIOKO}$, Ben. The right of intervention under the African Union's Constitutive Act: From non-interference to non-intervention. RICR. Vol. 85, n.852, 2003, pp 807-825;

RIBEIRO, Cláudio Oliveira. União Africana: possibilidades e desafios. Palestra proferida por ocasião do Seminário África, promovido pela Fundação Alexandre de Gusmão em parceria com o Instituto de Pesquisa em Relações Internacionais, em 02.03.2007. Disponível em: http:// www.funag.gov.br/Eve/ii-conferencia-nacional-de-politica-externa-e-politica-internacional/ seminarios/africa-02-02-2007

SADER, Emir et al. (Org.). Latinoamericana: Enciclopédia Contemporânea da América Latina e do Caribe. São Paulo: Boitempo, 2007;

SOUZA, André Matheus; ZACCARON, Beatriz Ávila. A participação do Brasil em missões de manutenção de paz: o caso Haiti. Clóvis Brigagão e Domício Proença Jr. O Brasil e os novos Conflitos Internacionais. Rio de Janeiro: Gramma: Fundação Konrad Adenauer, 2006;

SEITENFUS, Ricardo A.S. Fundamentos e desafios do Direito Internacional do Desenvolvimento. Novas disciplinarizaçôes do Direito Internacional. Lier Pires Ferreira Jr. E Luis Ivani de Amorim Araújo. Curitiba: Juruá, 2005, p.267-282;

SEITENFUS, Ricardo A.S. Pronunciamento na Sessão Especial sobre os Princípios de direito internacional contidos na Carta da OEA, em Washington, em 22 de março de 2007. Disponível em: <http://scm.oas.org/doc_public/PORTUGUESE/HIST_07/ CP18081P08.doc>. Acesso em: 3 jul. 2007. 
UNIĀO AFRICANA. Acto Constituctivo da União Africana. 2002;

VIZENTINI, Paulo Fagundes. O Brasil e as noçôes de Soberania e Não-Intervenção. In CADERNOS ADENAUER. Segurança e Soberania. Ano II, n.05; 2001;

WILLIAMS, Paul D. From non-intervention to non-indifference: the origins and development of the African Union's security culture. African Affairs. Oxford University Press, 2007. Acesso originalmente publicado online em 12 de Maio de 2007;

ZANELLA, Cristine Koehler; MARQUES, Pâmela Marconatto. Evo Morales e o País que quer existir: a legitimidade da nacionalização do gás e petróleo bolivianos em uma abordagem interdisciplinar. MENEZES, Wagner (Coord). Estudos de Direito Internacional:Anais do $4^{\circ}$ Congresso Brasileiro de Direito Internacional. Vol VI. Curitiba: Juruá, 2006.pp 510-515.

\section{Resumo}

O presente artigo consiste na tentativa de buscar um traço comum às experiências africana e brasileira em relação àquele que vem sendo chamado, nas relações internacionais contemporâneas, Princípio da Não-Indiferença. A escolha se justifica por se tratar de um Princípio jovem, que enseja a revisão de alguns dos conceitos clássicos do Direito Internacional Tradicional, tais como a Não-Intervenção e a Soberania, carecendo, portanto, de teorização e reflexão que ampare sua aplicação.

\section{Abstract}

The article is an attempt to find a commonality among African and Brazilian experiences towards what is termed, in cotemporary International Relations, the Principle of NonIndifference. The subject of analysis is chosen for its cutting edge quality and its challenge to some of Traditional International Law's concepts, such as Non-Intervention and Sovereignty Its novelty calls for reflection in its support.

Palavras-chave: Não-indiferença, não-intervenção, direito internacional. Key Words: Non-indifference, non-intervention, international law. 